\title{
Comment
}

\section{Engagement tools for scientific governance}

\author{
Andrea Bandelli
}

Museums have a great potential to facilitate the political engagement of citizens, intended not in the sense of taking part to the "party politics", but as full participation in the systems that define and shape society.

Some institutions take this role at their core: for example, the Science Museum of Minnesota recently developed a new mission statement to define the institution which says: "Turn on the science: realizing the potential of policy makers, educators, and individuals to achieve full civic and economic participation in the world." However at the moment such a mission statement is rather the exception than the rule among science centers and museums.

Instead, what is still common in the field is a certain ambiguity, or tension, in the role of science centers: on the one hand a strong willingness to be "agents of change"; on the other hand, the fear of losing neutrality and of compromising their impartiality.

In reality what is at risk when this ambiguity is not addressed and understood is not the neutrality of science centers, but rather their relevance and meaningfulness. Science centers risk to become stuck in what James Wildson calls "the shallow waters" of science engagement, a situation characterized by a "well-meaning, professionalized and busy field, which never quite impinges on fundamental practices, assumptions and routines."

Are science centers able to effectively interface the public with policy making? Are they "safe places for difficult conversations", because they care about the outcomes of these conversations or because the context in which these conversations take place is sterile and adverse to risk (and therefore "safe", at least from the institution's point of view)?

Thus, the challenge for science centers today is how to balance the social and to some extent political role that they should play as institutions contributing to the democratic development of science, with the humility necessary to be more embedded and relevant in the social structure where they operate. ${ }^{3}$

Rather than providing a role for the public in participatory processes and mechanisms designed from the top, science centers today ought to be part of and contribute to the dynamic governance that is necessary to sustain knowledge and innovation in our society, and consequently structure their own activities and ultimately their governance in a way that is coherent with these aims.

\section{"Decide" - an experiment in empowering civic and social action}

These issues are at the basis of the work that Ecsite, the European network of science centers and museums started in 2004 with the project "Decide - Deliberative Citizens' Debates", which represents an experimental approach to better understand the role of science centers in the democratization of science and the tensions and challenges in this field.

Before going into a description of "Decide", it is important to note that this is a network project rather than an institutional one. That is, the strategy for the project comes from a collaborative effort that involves several institutions and organizations, many of which are museums and science centers, but also associations, advocacy groups, and non governmental organizations.

The benefits of this approach are twofold. On the one hand, it is a way to distribute the risk of the activities. On the other hand, network projects allow for continuity in time across different funding sources and institutional commitments. A good metaphor for projects like "Decide" is the difference between a jazz band and an orchestra: all players have crucial roles in both, but while the orchestra plays under the leadership of a conductor, a jazz band shares that leadership and shifts it among its members.

When the project "Decide" started in 2004, it had three goals: to raise awareness among the public and the science center professionals for participatory and deliberative consultations; to collect data from 
debates and discussion on contemporary and controversial science issues; and to create an affordable and easy instrument to conduct debates and discussions in science centers.

The partners of "Decide" teamed up with the New Economics Foundation, an organization based in London that had previously developed a game called "Democs", which allowed small groups to conduct discussions and deliberations on controversial topics.

In "Decide", participants use cards that contain information, facts, issues and stories to discuss their point of view about a topic such as nanotechnology, the use of stem cells in research or the criminal liability of people with HIV. Then they use the same cards to develop a group response to different policies and if they want, they can develop their own policy.

There are three main phases during Decide. The first one is to clarify one's own personal position about an issue. By reading the different cards on the table, people start to ask themselves questions such as "What aspects are more interesting to me? Which facts do I already know, and which ones are new? What issues seem more problematic than others?" This phase is helpful to create a common ground among the participants, to "seed" equal starting points for further discussions among the participants. Regardless of the previous knowledge about the topic that people have, this phase, in the words of one participant, "gives people permission to talk". It is an effective definition for a very important process, which we could also call empowerment of the public, in the sense that it allows people who would normally stay away from a conversation because they think they have nothing to say, to instead meaningfully participate in a discussion, bringing their own perspective and experiences around items and facts that are shared by the whole group.

The second phase is a group discussion, where the participants engage in a tight conversation to identify what are the issues where they can converse and deepen their mutual knowledge, focusing on what are their common concerns, rather than their differences. This is the moment where the personal values of the participants are confronted with social values, in a process of listening and talking that involves the whole group. The cards on the table act as a catalyst to start the discussion; they represent common items of concern and interest for the group. During this phase it is not unusual for the discussion to open up in new directions: for example, during a "Decide" event on the use of stem cells in research, the group's position was to create a policy that would include biodiversity, and not only human health, as a goal for stem cells research - a radical departure from the usual debate that revolves around the use of stem cells from human embryos or cloning.

The third phase of "Decide" is the deliberative part of the game. On the basis of the discussion, the participants arrange the cards used during the game in clusters that represent common areas of concern and interest for the group. A cluster can be for example the role played by developing countries in the research field, or alternatives to the proposed research, or its impact on the environment. This process helps the group to reduce the issues that have been so far identified to a manageable number, and it represents an important process in policy making, the fact that at a certain point it is necessary to discard options in order to reach a shared conclusion. After the clustering process, the participants vote on a set of pre-defined policies, and are encouraged to create their own policies if they wish.

During the first two years, "Decide" was basically a tool: an instrument by which any organization could set up the process described above; most of the times however the discussions were disconnected from actual policy making. "Decide" was a good way to introduce deliberation; people enjoyed discussing about the different topics, but there was obviously a very weak link, if one at all, between the engagement of the participants with the subject, and the relevancy of the discussion in actual, social terms. "Decide", just as its aims stated, was good at raising awareness for deliberation as a method to present and discuss contemporary science and technology.

Then, starting from 2007, we noticed a radical development.

Several of the users of "Decide" became developers and they broadened considerably the purpose for which "Decide" was used. Museums and other organizations started to create their own kits to tackle local and pressing issues such as urban garbage disposal or immigrants and social integration, working in collaboration with the local authorities and institutions responsible for those issues. Others adapted and modified the existing kits and used them in a local context: for example, prisons and homeless shelter organizations in Vienna worked with the Austrian science center network to adapt the HIV kit and use it to "give a voice" to the homeless and convicts in regards to the HIV/AIDS policy at shelters and prisons. Several schools and universities used "Decide" as a training tool for young researchers to address the social implications of their work and teachers used them in the classroom with the students. 
The most significant example of this development is the collaboration that Eurordis, the European network of rare diseases, has established with Ecsite to use "Decide" in more than 800 debates across Europe that will bring together patients of rare diseases, families, care takers and health providers. The goal of this action ${ }^{6}$ is to strengthen the argumentative skills of patients and their families through the debates that will take places in museums and other venues in the course of 2010 and 2011, and at the same time to shape and inform the policy recommendations and advice that Eurordis and the national patients organizations bring to the European Parliament.

We recognized that a shift was taking place: "Decide" was changing from a project where museums made available a tool that users could employ for their own purposes, to a process of much more meaningful and relevant civic actions that relied on the co-development by the users themselves

We also realized the limits of the approach taken so far. The kits were released with a Creative Commons license that allowed free distribution for non-commercial use, ${ }^{7}$ but their content was still protected by the museums: according to the license, users were actually not allowed to modify the kits, in order to protect the validity of the content.

But the review of the many initiatives that evolved from "Decide" made it clear that this was an unfounded fear. The strength of "Decide" lies in the centrality of its purpose: although it is a playful activity, it is however a "serious game", it requires time, commitment, and the participants develop expectations that their action has been valuable. When it fails it is not because the content is not up to certain standards, but because the purpose is not allowed to emerge. The purpose drives the content, not the other way around.

Moreover, the network strategy on which "Decide" relies is built on the mutual trust among the participants; protection measures carry a high risk of diminishing the trust, setting rules that come in conflict with the needs of the users. In a similar way to what happens on the web with sites like Wikipedia, with "Decide" a small community of active developers, loosely connected with each other but trusting their mutual work, creates products that are enjoyed by a much larger group of users.

\section{An experimental approach}

In light of this, in 2009 three major decisions to steer the development of "Decide" were taken to validate these observations.

The first was to use a more relaxed open source license that allows for modification, distribution and even for commercial derivatives of "Decide", provided that the source is acknowledged and that the products are released with the same open source license. ${ }^{8}$ This in fact represents relinquishing the control on "Decide" and sharing it with the public. The rationale is that in order to sustain the purpose of "Decide" and foster innovation in how the public participate in policy and decision making about science, we need to open up the creative process to the public and allow for unplanned and unanticipated uses and developments of "Decide".

The second was to create a series of "microgrants" of about $€ 2,500$ to support the users to become "brokers" and connect together local organizations, networks and institutions to strengthen the relevance of their activities. The purpose of the microgrants is to embed the use of "Decide" in local issues, where participation connects with the policy and decision making processes. The microgrants are the catalysts to encourage innovation, and a cost effective measure to sparkle creativity and collaborations.

The third was to provide training and professional development resources to museum staff and other organizations in order to internalize a culture of dialogue and participation and start a process of aligning the institutional internal practices with their external actions. ${ }^{9}$

These three actions, combined with the availability of an online system that allows anybody to create a full "Decide" kit (integrating the design, layout and editing tools), are at the moment an experiment for the science centers in Europe to implement a devolved and networked approach to civic action, and to share with their public the authority they used to hold for themselves.

We can already witness how this approach is actually empowering a whole range of actors to build on the experience and knowledge developed with "Decide" and innovate their approach to science engagement. The strength of a project like "Decide" is in its role as a catalyst to inspire many (and often small) actors to contribute with their activities to the discourse on the governance of science.

Discussion games trigger conversations and deliberations among the players, but they also strengthen the capacity of many organizations and institutions to play an active role in this domain, a role which 
goes beyond the plain organization of debates but looks also at how the knowledge generated in these debates is fed back into the policy making system. This is by no means an easy role, and we are just discovering some of the possibilities, pitfalls and challenges that lie ahead.

The case studies and the interviews in this issue of JCOM document the innovation and the engagement level in the field - the engagement of the public with science certainly, but most important the engagement of the science centers with the public, their willingness to overcome institutional inertia and to participate responsibly and in first person in the discussions and debates they promote.

\section{Notes and references}

1 "Public Engagement in Science - Report of the Science in Society Session of the Portuguese Presidency Conference "The Future Of Science And Technology In Europe", Lisbon, 8-10 October 2007”. European Commission, 2008, p. 20.

http://ec.europa.eu/research/science-society/document_library/pdf_06/public-engagement-081002_en.pdf, accessed on 26 May 2010

2 As mentioned in the 2008 Toronto Declaration, endorsed by all the science center networks worldwide

(http://www.5scwc.org/TheTorontoDeclaration/tabid/133/Default.aspx, accessed on 26 May 2010)

3 E. Koster and J. Falk (2007), Maximizing the external value of museums, Curator 50:191.

4 A. Bandelli, E.A. Konijn and J.W. Willems (2009), The need for public participation in the governance of science centers,

Museum Management and Curatorship, 24(2): 89.

5 Decide was originally developed by At Bristol, Heureka, Cité des Science et de l'Industrie, Fondazione IDIS and Ecsite.

$6 \mathrm{http}$ ://www.eurordis.org/content/polka-patients-consensus-preferred-policy-scenarii-rare-disease, accessed on $26 \mathrm{May} 2010$.

7 http://creativecommons.org/licenses/by-nc-nd/2.5/

$8 \mathrm{http} / / /$ creativecommons.org/licenses/by-sa/3.0/

9 These actions are funded by the European Commission in the framework of the "FUND" project,

http://www.playdecide.eu/about.

\section{Author}

Andrea Bandelli has a wide international experience in developing, managing and leading collaborative projects and initiatives in the field of science communication and public engagement with science. He has worked with several public and private organizations in Europe, USA, Brazil and South Africa for projects including exhibitions, international conferences, training programs and innovative actions fostering democracy and participation.

His current academic research focuses on the role of the public in the governance of science centres and museums. Since 2004 he is the leader of "Decide", an international initiative to sustain participation, dialogue and democracy in science and technology.E-mail: andrea@bandelli.com, http://www.bandelli.com.

How TO CITE: S. Bandelli, Engagement tools for scientific governance, by playing, Jcom 09(02) (2010) C01 